\title{
Granulocyte-colony stimulating factor-producing squamous cell carcinoma arising in ovarian mature cystic teratoma: A case report*
}

\author{
Satoshi Ichigo ${ }^{1}$, Hiroshi Takagi ${ }^{1}$, Kazutoshi Matsunami ${ }^{1}$, Takayuki Murase ${ }^{2}$, Tsuneko Ikeda $^{2}$, \\ Atsushi Imai ${ }^{1 \#}$ \\ ${ }^{1}$ Departments of Obstetrics and Gynecology, Matsunami General Hospital, Gifu, Japan \\ ${ }^{2}$ Departments of Pathology, Matsunami General Hospital, Gifu, Japan \\ Email: "aimai@matsunami-hsp.or.jp
}

Received 24 October 2013; revised 17 November 2013; accepted 21 November 2013

Copyright (C) 2013 Satoshi Ichigo et al. This is an open access article distributed under the Creative Commons Attribution License, which permits unrestricted use, distribution, and reproduction in any medium, provided the original work is properly cited.

\begin{abstract}
Granulocyte-colony stimulating factor (G-CSF)-producing cancer has been reported to occur in various organs. It has an aggressive nature and shows resistance to conventional treatments, however, its clinical features are not well known because of the small number or reported cases. We report G-CSF-producing squamous cell carcinoma arising in malignant-transformed ovarian mature cystic teratoma. An 80-year-old woman underwent suboptimal surgical excision of stage IIIC ovarian cancer. Prior to the treatment, the patient presented severe granulocytosis and elevated serum G-CSF concentration. With the help of histopathological and immunohistochemical studies, we diagnosed this case to be a poorly differentiated squamous cell carcinoma developed in ovarian mature cystic teratoma, which highly expressed G-CSF. During radiation therapy, the patient died from rapid growth of residual tumor and peritoneal dissemination 2 months after surgery. This is the first case of G-CSF-producing squamous cell carcinoma arising in malignant-transformed ovarian mature cystic teratoma, and its prognosis was very poor.
\end{abstract}

Keywords: G-CSF-Producing Cancer; Malignant Transformation of Mature Cystic Teratoma; Squamous Cell Carcinoma; Ovarian Cancer

\section{INTRODUCTION}

Granulocyte-colony stimulating factor (G-CSF)-pro-

*Conflict of interest: The authors have no conflict of interest to disclose.

${ }^{\#}$ Corresponding author. ducing tumor arises from various organs (e.g. lung, stomach, esophagus, gall bladder, thyroid, urinary bladder, liver, uterine cervix, colon) [1-6]. This type of tumor produces various cytokines including G-CSF, and induces severe granulocytosis as a paraneoplastic syndrome. G-CSF-producing tumors exhibit significant hyperplastic and metastatic properties and have a very poor prognosis. It has also been reported that many G-CSFproducing tumors are resistant to conventional treatments $[3,5,7]$.

To our knowledge, G-CSF-producing malignant-transformated ovarian mature cystic teratoma has never been reported in the English literature. Malignant transformation of a mature cystic teratoma is an uncommon complication occurring in approximately $1 \%-3 \%$ of all mature cystic teratoma $[8,9]$ and thought to have a very poor prognosis. Although any of the constituent tissues of teratoma has the potential to undergo malignant transformation, squamous cell carcinoma is the most commonly associated cancer. Because of its very poor prognosis, it appears justified to report an additional and rather unusual case of G-CSF-producing ovarian cancer, and to focus some attention on this type of neoplasm.

\section{CASE REPORT}

The patient was an 80-year-old woman (gravida 2, para 2) who had complained of lower abdominal distention for about 2 months and visited our department. The physical examination revealed a large, poorly movable, nontender abdominal tumor. The upper margin of the tumor extended to about several $\mathrm{cm}$ above the navel.

As shown in Figure 1, the huge spherical tumor was revealed with markedly high signal intensities in T2weighted images. It was clearly distinguished from the 


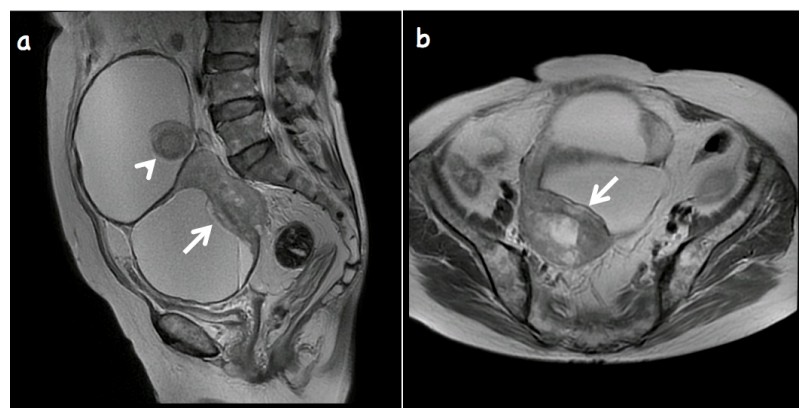

Figure 1. Sagittal (a) and transaxial (b) T2-weighted magnetic resonance images shows multilocular mature cystic teratoma. Nodular projection of low signal intensity (arrow) shows transmural extension and extends into adjacent loculus. Hair ball is observed (arrowhead).

smaller uterus. The tumor was considered an ovarian cystic tumor containing fat and hair ball. The posterior margin of the solid portion was irregular, and extracapsular extension was suspected. Ascites were not retained in the pelvic cavity.

A pre-treatment blood test showed the following: white blood cell (WBC) $37.63 \times 10^{3} / \mathrm{mm}^{3}$ (normal 3.0 9.0); hemoglobin (Hb) $6.8 \mathrm{~g} / \mathrm{dl}$ (normal 12.0 - 15.0); CRP $6.5 \mathrm{mg} / \mathrm{dl}$ (normal < 0.30); SCC $1.1 \mathrm{ng} / \mathrm{ml}$ (normal < 1.5); CA125 $18.9 \mathrm{U} / \mathrm{ml}$ (normal < 35); CEA $3.0 \mathrm{ng} / \mathrm{ml}$ (normal $<5.0$ ). She had no symptoms of infectious disease, no recent history of drug intake. Immature granulocytes suggestive of leukemia were not detected in peripheral blood. Blood biochemical examination demonstrated markedly elevated serum G-CSF of $486 \mathrm{pg} / \mathrm{ml}$ (normal < 39.0) and tumor necrotic factor (TNF)- $\alpha$ of 9.8 $\mathrm{pg} / \mathrm{ml}$ (normal 0.6 - 2.8). From these results, it was considered that her ovarian tumor was a G-CSF-producing tumor. Gastroduodenoscopy and colonoscopy were normal. The endometrial biopsy showed negative.

Exploratory operation was planned with the provisional diagnosis of a malignant transformation of mature cystic teratoma, based on the age of patient and MRI findings of large solid component suggestive for transmural extension into adjacent tissues. During the operation, $100 \mathrm{ml}$ of bloody ascitic fluid was drained from the patient. Cytologic examination of the ascites was positive. A smooth-surfaced, huge cystic tumor measuring 15 $\times 10 \times 14 \mathrm{~cm}$ was found to originate in the right ovary. The greater omentum was matted and severe invasive adhesion was found between the tumor and pelvic wall. The uterus and left ovary appeared normal; however, tumor seeding was suspected due to some neogrowths on the surface of the bladder and rectum. We performed suboptimal debulking surgery, total hysterectomy with bilateral salpingoophorectomy and partial omentectomy.

Microscopically, the tumor was covered with benign keratinizing squamous epithelium and surrounded by sebaceous glands and hair follicles, which proved the tu-

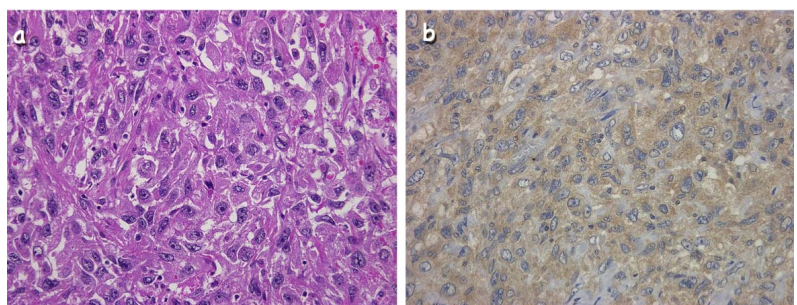

Figure 2. Histological and immunohistochemical findings of the surgical specimen. (a) Poorly differentiated squamous cell carcinoma (hematoxylin-eosin staining, $\times 400$ original magnification). (b) Immunohistochemical staining with a specific monoclonal antibody against G-CSF was positive in tumor cell cytoplasm and interstitial spaces $(\times 400$ original magnification).

mor was a mature cystic teratoma. However, the solid portion comprised spindle cells with prominent nuclear atypia and frequent mitotic features showing sarcomatoid features. Squamous cell carcinoma nests were scattered against sarcomatoid elements (Figure 2). Immunohistological study showed a high expression of G-CSF in the tumor cells and interstitial spaces (Figure 2). From these findings, we concluded that this tumor was a GCSF-producing ovarian cancer, and the case was classified as FIGO clinical stage IIIC.

The patient's advanced age suggested no indication of chemoradiotherapy. During the whole pelvic radiotherapy, her general condition suddenly deteriorated, and dies from rapid growth of residual tumor and peritoneal dissemination 2 months after surgery.

\section{DISCUSSION}

Some malignant tumors may produce G-CSF and induce severe granulocytosis. The diagnostic criteria for G-CSFproducing tumor are the following: 1) extereme granulocytosis; 2) elevated serum G-CSF levels; and 3) proof of G-CSF production within the tumor cells [10]. Our case met all the criteria, confirming that the patient presented with G-CSF-producing ovarian cancer.

G-CSF-producing tumors are considered to have a poor prognosis, due to the effects of G-CSF on proliferating tumor cells and enhancement of metastasis. G-CSF may therefore accelerate the clinical progression of the disease $[2,10]$. Tachibana et al. showed that G-CSF production by transitional cell carcinoma of the bladder augments autocrine growth, which may in part explain the poor prognosis [12]. Savarese et al. reported that $56.5 \%$ of primary ovarian carcinoma co-expressed GCSF and the G-CSF receptor; potential autocrine and/or paracine loops involving G-CSF and its receptor occur in over $90 \%$ of primary ovarian carcinomas [13]. Furthermore, Natori et al. reported that G-CSF stimulates angiogenesis and promotes tumor growth [14]. The production of G-CSF by squamous cell carcinoma cell lines was 
closely related to their in vitro invasiveness [15]. For these reasons, G-CSF-producing cancer has a very poor prognosis, and at the present time, there is no specific approach for G-CSF-producing cancer. The patient in the present study also exhibited sudden enlargement of the residual tumor after surgery, accompanied by deterioration of her general condition.

The most common sign of mature cystic teratoma with malignant transformation may be a pelvic mass without any specific symptoms. However, some clinical features of this event have been reported. First, this tumor is age related; although the ages of patients with this tumor ranged from 21 to 87 years in the literature, this tumor occurs most frequently in postmenopausal women [1619]. Second, tumor size is an important factor contributing to a differential diagnosis between a malignant and mature cystic teratoma [16-19]. In report by Kikkawa et $a l$., a squamous cell carcinoma developing from a mature cystic teratoma was significantly larger than a mature cystic teratoma; the mean size of 37 squamous cell carcinomas developing from mature cystic teratoma was $152.3 \mathrm{~mm}$; and the cutoff size between benign and malignant was $99 \mathrm{~mm}$ [16]. The gross appearance of mature cystic teratoma with malignant transformation has been reported to resemble that of cystic teratoma but tends to be more solid. The present case also had an obvious solid component and was relatively large. The age of patient and the MRI findings were helpful in the preoperative diagnosis of mature cystic teratoma with malignant transformation.

In summary, we presented the first case of G-CSFproducing squamous cell carcinoma arising in ovarian mature cystic teratoma. Its prognosis is very poor, and conventional treatments including radiation therapy have no effect. The findings of the present study indicate that in solid-malignancy patients who develop leukocytosis and elevated CRP, it is important to make an early differential diagnosis between inflammatory disease and GCSF-producing tumors.

\section{REFERENCES}

[1] Takahashi, H., Yasuda, A., Ochi, N., Sakamoto, M., Takayama, S., Wakasugi, T., Funahashi, H., Sawai, H., Satoh, M., Akamo, Y. and Takeyama, H. (2008) Granulocyte-colony stimulating factor producing rectal cancer. World Journal of Surgical Oncology, 6, 70-74. http://dx.doi.org/10.1186/1477-7819-6-70

[2] Kobayashi, J., Miyazaki, A., Yamamoto, T., Nakamori, K., Suzuki, R., Kaneko, T., Suzuki, N. and Hiratsuka, H. (2012) Granulocyte colony-stimulating factor-producing squamous cell carcinoma of the lower gingiva: A case report. Head and Neck Oncology, 4, 35-40. http://dx.doi.org/10.1186/1758-3284-4-35

[3] Ohkubo, Y., Kato, S., Kiyohara, H., Suzuki, Y., Nakano,
T. and Kamada, T. (2013) Granulocyte-colony stimulating factor-producing cervical cancers treated with carbon-ion irradiation. Journal of Obstetric and Gynaecological Research, 39, 1111-1115.

http://dx.doi.org/10.1111/jog.12024

[4] Hasegawa, S., Suda, T., Negi, K. and Hattori, Y. (2007) Lung large cell carcinoma producing granulocyte-colony-stimulating factor. Annals of Thorac Surgery, 83, 308-310.

http://dx.doi.org/10.1016/j.athoracsur.2006.04.049

[5] Yamano, T., Morii, E., Ikeda, J. and Aozasa, K. (2007) Granulocyte colony-stimulating factor production and rapid progression of gastric cancer after histological change in the tumor. Japan Journal of Clinical Oncology, 37, 793-796. http://dx.doi.org/10.1093/jjco/hym094

[6] Araki, K., Kishihara, F., Takahashi, K., Matsumata, T., Shimura, T., Suehiro, T. and Kuwano, H. (207) Hepatocellular carcinoma producing a granulocyte colony-stimulating factor: report of a resected case with a literature review. Liver International, 27, 716-721. http://dx.doi.org/10.1111/j.1478-3231.2007.01468.x

[7] Matsumoto, Y., Mabuchi, S., Muraji, M., Morii, E. and Kimura, T. (2010) Squamous cell carcinoma of the uterine cervix producing granulocyte colony-stimulating factor: A report of 4 cases and a review of the literature. International Journal of Gynecological Cancer, 20, 417421. http://dx.doi.org/10.1111/IGC.0b013e3181d15a11

[8] Griffiths, D., Wass, J., Look, K. and Sutton, G. (1995) Malignant degeneration of a mature cystic teratoma five decades after discovery. Gynecologic Oncology, 59, 427429. http://dx.doi.org/10.1006/gyno.1995.9948

[9] Kido, A., Togashi, K., Konishi, I., Kataoka, M., Koyama, T., Ueda, H., Fujii, S. and Konishi, J. (1999) Dermoid cysts of the ovary with malignant transformation: MR appearance. American Journal of Roentgenology, 172, 445-449. http://dx.doi.org/10.2214/ajr.172.2.9930800

[10] Asano, S., Urabe, A., Okabe, T., Sato, N. and Kondo, Y. (1977) Demonstration of granulopoietic factor(s) in the plasma of nude mice transplanted with a human lung cancer and in the tumor tissue. Blood, 49, 845-852.

[11] Tsuzuki, H., Fujieda, S., Sunaga, H., Noda, I. and Saito, H. (1999) Expression of granulocyte colony-stimulating factor receptor correlates with prognosis in oral and mesopharyngeal carcinoma. Cancer Research, 58, 794800.

[12] Tachibana, M., Miyakawa, A., Tazaki, H., Nakamura, K., Kubo, A., Hata, J., Nishi, T. and Amano, Y. (1995) Autocrine growth of transitional cell carcinoma of the bladder induced by granulocyte-colony stimulating factor. Cancer Research, 55, 3438-3443.

[13] Savarese, T., Mitchell, K., McQuain, C., Campbell, C., Guardiani, R., Wuu, J., Ollari, C., Reale, F., Nelson, B., Chen, A. and Quesenberry, P. (2001) Coexpression of granulocyte colony stimulating factor and its receptor in primary ovarian carcinomas. Cancer Letters, 162, 105115. http://dx.doi.org/10.1016/S0304-3835(00)00623-6

[14] Natori, T., Sata, M., Washida, M., Hirata, Y., Nagai, R. and Makuuchi, M. (2002) G-CSF stimulates angiogenesis and promotes tumor growth: Potential contribution of 
bone marrow-derived endothelial progenitor cells. Biochemical and Biophysical Ressearch Communication, 297, 1058-1061.

http://dx.doi.org/10.1016/S0006-291X(02)02335-5

[15] Tsuruta, N., Yatsunami, J., Takayama, K., Nakanishi, Y., Ichinose, Y. and Hara, N. (1998) Granulocyte-macrophage-colony stimulating factor stimulates tumor invasiveness in squamous cell lung carcinoma. Cancer, 82, 2173-2183.

http://dx.doi.org/10.1002/(SICI)1097-0142(19980601)82: $11<2173::$ AID-CNCR12>3.0.CO;2-R

[16] Kikkawa, F., Nawa, A., Tamakoshi, K., Ishikawa, H., Kuzuya, K., Suganuma, N., Hattori, S., Furui, K., Kawai, M. and Arii, Y. (1998) Diagnosis of squamous cell carcinoma arising from mature cystic teratoma of the ovary. Cancer, 82, 2249-2255.

http://dx.doi.org/10.1002/(SICI)1097-0142(19980601)82:

\section{1<2249::AID-CNCR21>3.0.CO;2-T}

[17] Takemori, M. and Nishimura, R. (2003) MRI findings of an ovarian dermoid cyst with malignant transformation. Magnetic Resonance in Medical Sciences, 2, 105-108. http://dx.doi.org/10.2463/mrms.2.105

[18] Tseng, C., Chou, H., Huang, K., Chang, T., Liang, C., Lai, C., Soong, Y., Hsueh, S. and Pao, C. (1996) Squamous cell carcinoma arising in mature cystic teratoma of the ovary. Gynecologic Oncology, 63, 364-370. http://dx.doi.org/10.1006/gyno.1996.0337

[19] Takagi, H., Ichigo, S., Murase, T., Ikeda, T. and Imai, A. (2012) Early diagnosis of malignant-transformed ovarian mature cystic teratoma: Fat-suppressed MRI findings. Journal of Gynecological Oncology, 23, 125-128. http://dx.doi.org/10.3802/jgo.2012.23.2.125 